\title{
Two approaches to the problem of universals by J. M. Bocheński
}

\author{
Mariusz Grygianiec
}

Published online: 22 August 2013

(C) The Author(s) 2013. This article is published with open access at Springerlink.com

\begin{abstract}
The main aim of the paper is to reconstruct and analyse two methodological approaches to the problem of universals, presented in Bocheński's papers "Powszechniki jako treści cech w filozofii św. Tomasza z Akwinu" and "The Problem of Universals." It is argued that, although these approaches are rather different from historical and methodological points of view, they are still based on the same ontological ground, viz. on immanent realism. The article provides a detailed analysis and comparison of the respective views. Justification is provided for the claim that Bocheński was an immanent realist and some of Bocheński's detailed solutions are highlighted that may be of particular importance for further debate over the problem of universals. A couple of minor critical comments concerning some of Bocheński's analyses are presented at the end of the paper.
\end{abstract}

Keywords Bocheński · Universals · Property · Identity · Nominalism · Realism · Object

\section{Introduction}

In defiance of suggestions that may arise in connection with the title of this paper, I am going to argue that throughout his entire creative life Józef Bocheński maintained a uniform metaphysical view with regard to universals. He was an advocate of moderate universal realism, in contemporary terminology also called immanent realism. The reason why two approaches to the problem of universals will be discussed is that in his considerations on the subject, which he undertook systematically on two occasions, Bocheński used two different methods and manners of analysis.

M. Grygianiec ( $₫)$

Institute of Philosophy, University of Warsaw, Krakowskie Przedmieście 3, 00-927 Warsaw, Poland e-mail:mgrygian@uw.edu.pl 
I am going to formulate and justify a few claims concerning Bocheński's metaphysical and methodological views presented in two of his papers, which deal directly with the problem of universals, namely "Powszechniki jako treści cech w filozofii św. Tomasza z Akwinu" (Universals as contents of properties in St. Thomas Aquinas's philosophy) ${ }^{1}$ (Bocheński 1938, PTC for short) and "The problem of universals" (Bocheński 1956, ZP respectively). Some of Bocheński's comments in two other papers, namely "Zagadnienie przyczynowości u neoscholastyków" (Neo-scholastics on the problem of causality) (Bocheński 1935) and "On the syntactical categories" (Bocheński 1949) are also devoted to the topic. Due to their subsidiarity the last two papers will not figure in my analysis.

It is worth noting that Bocheński's inquiries about the existence and nature of universals belong to the wider polemic context, which can be described as the debate over universals in the Lvov-Warsaw School. Bocheński's analyses-apart from those of Ajdukiewicz (1930, 1932, 1934), Łukasiewicz (1910) or Borowski's (1921) — are located on the realist side and in opposition to the nominalist fraction represented by Leśniewski (1913), Kotarbiński (1921), ${ }^{2}$ and Lejewski (1990).

\section{Ontological individualism}

Bocheński regarded the thesis of ontological individualism as the metaphysical context for many philosophical considerations. The problem of universals was no exception. The basic claim, speaking roughly, is that each object is an individual object. $^{3}$ This thesis should be distinguished from a similar nominalist thesis. Firstly, the thesis of individualism does not exclude other ontological categories, in particular, properties or events. Secondly, it does not exclude the existence of complex objects, which have general, non-individual objects as parts. Rather, the thesis is that among really existing objects (substances) there are no objects of a general or abstract nature.

The thesis of ontological individualism is crucial for a proper understanding of Bocheński's metaphysical views. However, it may appear to be in conflict with another thesis Bocheński held, namely, his claim that the world has a stratified structure; it is composed of objects and properties, which characterize them (Bocheński 1956 97). Now, the conflict is only apparent. According to Bocheński, properties exist, but they are not things. Furthermore, as it will turn out later, properties occur in many forms: they are both abstract contents and particular qualities of objects.

The other important role of the thesis under consideration is that it stands opposed to reductive analyses, typical of Polish nominalists who, following Twardowski (Twardowski 1894), defined universals inter alia as general objects. According to one version of the nominalist argument, a general object with respect to the set of

\footnotetext{
${ }^{1}$ In Polish philosophical literature this paper has a short elaboration in (Wolak 1993, 141-143).

2 On additional information on Kotarbiński's analyses see e.g. (Grygianiec 2001).

${ }^{3}$ Compare Bocheński's words in ZP, p. 79: "The author is of the opinion that every object in the universe existing outside the mind is an individual object, not a general one."
} 
individual objects (at least two such objects) is an object which can possess only these properties which are common to all individual objects in question (Kotarbiński 1921, 104; Leśniewski 1913, 142). Prescinding from numerous issues hidden in the above formulation, it is worth noting that a universal is treated here both as an object and a general object. Anyone who accepts the existence of universals has to either abandon the thesis of ontological individualism or reject the above definition. It is therefore entirely understandable why in PTC Bocheński emphasizes-following St. Thomasthat "A universal is not a thing" (Bocheński 1938, s 138 and 139).

The thesis of ontological individualism likewise sheds light on the distinction between properties as particular qualities and properties as abstract contents. I will have more to say about this distinction below.

\section{Immanent realism}

In the debate on universals, immanent realism is-apart from nominalism, conceptualism, and extreme realism-one of the four classic positions. This doctrine is known also as moderate universal realism or Aristotelian realism. In broad outline the idea is that: (1) universals exist; (2) they are ontologically dependent upon objects which exemplify them (therefore they are not of a substantial nature; they exist only in so far as they are instantiated); (3) they are not of such a nature as to be necessary. As characterized, they are universals in rebus.

Immanent realists present considerable variation as to the more specific issues. Indeed, the above general formulation of the doctrine does not resolve the following issues: (a) how universals can be located in space; (b) whether they can enter into causal relations; (c) whether they can be observed; (d) whether they are hierarchically arranged; (e) whether there are conjunctional, disjunctional or negative universals; (f) whether there are any formal relations between them (i.e. entailment or inclusion). Both in PTC, ZP, and other papers, Bocheński has clearly stated his commitment to immanent realism. At the same time he distances himself from the extreme version of realism (Bocheński 1949, 278). ${ }^{4}$ Although Bocheński did not express his views regarding many of these specific issues, besides recognizing the existence of universals, he appeared to accept the exemplification principle ${ }^{5}$ and questioned the substantial nature of universals. He was especially concerned with the last issue, particularly in PTC, partly as a result of his polemics with Kotarbiński and Leśniewski.

\section{The theory of universals in PTC}

Bocheński begins the outline of the theory of universals by introducing an appropriate language. The language includes the following syntactic categories:

\footnotetext{
${ }^{4}$ Some researchers have suggested, however, that Bocheński was a supporter of the doctrine of Platonic realism. Compare in this connection e.g. (Jadacki 1998, 379).

5 This principle says that only exemplified universals exist. On this subject compare e.g. (Armstrong 2001, 65-69).
} 
a) individual variables (' $x$ ', ' $y$ ');

b) two-place sentential functors (' $\neq$ ', ' $=$ ');

c) one-place first level functors (' $\varphi$ ');

d) one-place second level functors (' $P$ ');

e) sentences (and sentence functions);

f) one-place sentence connectives (' $\sim$ ');

g) two-place sentence functors (' $\rightarrow$ ', ' $\wedge$ ');

h) quantifiers (' $\forall$ ', ' $\exists$ ').

The definition of a universal is the following:

(1) $P(\varphi)=\exists x, y[(\varphi x \wedge \varphi y) \wedge x \neq y]$,

which should be read: ' $\varphi$ is a universal' is the same as 'there are at least two different objects $x$ and $y$, such that $x$ is $\varphi$ and $y$ is $\varphi$ '.

The realist thesis has the form:

(2) $\exists \varphi \exists x, y[(\varphi x \wedge \varphi y) \wedge x \neq y]$.

This thesis should be read as follows: 'There is at least one such $\varphi$, that there are at least two different objects $x$ and $y$, such that $x$ is $\varphi$ and $y$ is $\varphi^{\prime}$.

The nominalist thesis would be negation of the thesis (2), thus:

(3) $\sim\{\exists \varphi \exists x, y[(\varphi x \wedge \varphi y) \wedge x \neq y]\}$.

According to Bocheński, the following thesis can be obtained from statement (3) deductively on the basis of any sufficiently developed two-valued system of logic:

(4) $\forall \varphi \forall x, y[(\varphi x \wedge \varphi y) \rightarrow \sim(x \neq y)]$,

so the thesis, that 'for any $\varphi$ and for any $x$ and $y$ : if $x$ is $\varphi$ and $y$ is $\varphi$, it is not true that $x$ is different from $y$ ' (Bocheński 1938, 147). According to Bocheński this would lead to paradoxes: two white things (e.g. a wall and a lump of sugar) would have to be identical; therefore, the names 'wall' and 'lump of sugar' would be names of the same thing. Furthermore, the same conclusion could be drawn for any two things with the same properties.

A substantial part of Bocheński's paper is devoted to interpreting the concept of 'universal' on the basis of St. Thomas Aquinas' text and to confront the interpretation with possible reist objections.

According to Bocheński, the main difficulties concerning universals result, as mentioned, from interpreting universals as things. St. Thomas's texts give clear solution: a universal is not a thing, but it is something which occurs in many things. Therefore a universal is a property-universale non significat hoc aliquid, sed quale (Bocheński 1938, 138).

Since a universal is a property (qualitas), and a property is a quality (accidens), and the essence of an object is defined by universals, then the essence itself is defined by qualities. The consequent of this conditional is not acceptable within the framework of Aristotle's and St. Thomas's ontology. Therefore, among all the qualities accidental qualities (qualitates accidentalis) have to be distinguished from 
substantial qualities (qualitates substantialis). Universals would constitute essential qualities, although they still would be properties (qualitatis).

Kotarbiński's arguments do not apply to universals interpreted in this way, because he implies that a universal is a thing. However, the following difficulty arises. It may be doubted not only whether there exist universals as things, but also whether there are any universals as properties. Bocheński says that he is perfectly certain about the existence of properties and if anyone doubts their existence this is due to two misunderstandings.

First, reists, for example, seem to identify the mode of existence of properties with the mode of existence of things. Bocheński writes that reists "seem to assume that when we say 'A property $\varphi$ exists' we assign to the word 'exists' exactly the same meaning which we associate with the equiform word when we read the sentence 'A donkey exists' " (Bocheński 1938, 139-140). ${ }^{6}$ According to Bocheński, no supporter of universals claims something of the sort. It is worth specifying that the function 'a property $\varphi$ exists' is tantamount to the function 'there is an $x$, such that a property $\varphi$ appears in $x$ - the function, which changes into a true sentence, when we substitute a word for the variable ' $\varphi$ ', for example 'white'.

Second, reists confuse the problem of the mode of existence of properties and things with the issue of the ontological difference between things and properties. The second of the topics mentioned, which Bocheński takes to be much more difficult than the others, is not connected with the issue of the existence of universals. ${ }^{7}$

There is a further difficulty. St. Thomas recognizes the meaningfulness of sentences the subject of which is the name of a universal. However, were a universal a property, its symbol would rather have to be a functor, not a functor's argument. It seems that in order to remove this difficulty it is possible to eliminate the artificial division into subject and predicate. For example the sentence 'A human is white' can without any complications be written as: 'For any $x$, if $x$ is a human, $x$ is white'. By that means, what had been a subject, is now a functor. Generalizing, we obtain the following formula:

Everything that possesses a property $\varphi$, also possesses a property $\psi$.

However, according to Bocheński, this approach is inaccurate. The point is that our language is too imperfect "to [...] be able to articulate and our mind to come to know all reality [...]" (Bocheński 1938, 148), including even the mere possession of a property by an object. Apart from that, any property of a particular object is also particular, ${ }^{8}$ whereas a universal is not of a particular nature. In the case of many

\footnotetext{
${ }^{6}$ A similar view has been expressed by Ajdukiewicz-compare (Ajdukiewicz 1934, 196-210).

7 Bocheński writes: "And so this problem has nothing to do with our question, at least according to St. Thomas, who, although he recognizes the ontological difference between properties and the things in which these properties appear, when it comes to universals, however, he claims quite clearly that they differ ontologically from things. Thus, for example, humanity is not different from a particular human. Of course, a reist will advance the following complaint: if a property is ontologically different from a thing, then how we can say that properties exist? But this objection demonstrates only that its author does not understand what a property is." Compare (Bocheński 1938, 140).

${ }^{8}$ Bocheński writes: "There are no general properties at all, i.e. occurring in several different things in the external world and each of them, as a result of bonding with that individuating factor, is strictly individual, utterly different from any other properties." Compare (Bocheński 1938, 148).
} 
objects what is general in property exemplification is a content of the property in question, not the property itself. Therefore, universals are not simply properties, but contents $^{9}$ of these properties. This, in turn, would suggest that the terminology introduced above is not perfectly adequate, because «the smallest» element of this terminology is the notion of property, not the notion of content of a property. Simultaneously this would also suggest that the terminology should be improved by introducing symbols denoting contents of properties.

However, according to Bocheński, such an intervention is not necessary, because our language is so structured that whenever we attribute properties to objects, we likewise attribute contents. We must therefore accept the relative inaccuracy of language. Consequently, according to Bocheński, there is no reason to distinguishon the level of formal reconstruction - a property from its content; "you only need to remember that when we say ' $\varphi$ is in $x$ ' we always understand ' $\varphi$ ' as a content, not a real quality with all its elements, appearing with it in an object-because such functors must not be used at all" (Bocheński 1938, 148-149).

The main objection to Bocheński's conception is that his definition of universals is too broad. In light of this definition, each property had by two non-identical individuals is a universal. Whereas, in fact, every property is a universal. Therefore, the following, preliminary question should be formulated: Are properties universals? In light of Bocheński's analysis this question should be answered negatively: properties are not universals; it is rather contents of properties that are universals.

In turn, the term content of a property—despite Bocheński's assurances—still remains unclear. Once we add to that the fact signaled by Bocheński himself-the fact, namely, that contents of properties can only be expressed in the terminology of properties - this confuses the matter even more. Moreover, we do not have any clear criterion here by which to determine when a given statement is about properties and when it is about the relevant contents of these properties. This observation is important, because, after all, there may be contexts in which we would like to talk about the properties, not about their contents. Therefore, there is-contrary to Bocheński's intentions - a need to for formal reconstruction of ontological issues, both in the terminology of properties and in that of their contents.

\section{The formulation of the problem of universals in ZP}

In 1956, Bocheński returned to the problem of universals in ZP, where he attempted to reformulate the relevant issue. Bocheński's article appeared in connection with the philosophical conference which took place in March of that year at the University of Notre Dame, Indiana. The congress was devoted entirely to the problem of universals and it two prominent philosophers took part: Alonzo Church—a Platonist, and Nelson Goodman (Bocheński 1993b)—a nominalist.

Bocheński claims that each approach to the problem of the existence of universals is relative to the chosen ontology. For his part, Bocheński assumes, as before, ontological individualism. The problem of universals boils down to the

\footnotetext{
9 Bocheński stated a similar idea in (Bocheński 1935).
} 
simple question: 'Do universals exist?' The answer to this question, however, depends on the meaning of the term 'universal'. Bocheński lists five possible "strata" of reality to which the term is sometimes applied:

(a) linguistic symbols (inscriptions or sounds as physical bodies);

(b) subjective mental entities (ideas);

(c) objective meanings (Stoic “ $\lambda \varepsilon \kappa \tau \alpha$ ”);

(d) phenomenal realities in the sense of Husserl;

(e) transcendent beings (existing outside of reality).

According to Bocheński, of those five "strata" the second and the fifth can be immediately excluded, as they are not suited for investigating the problem of universals. This is because subjective mental entities are real and concrete and transcendent beings remain beyond our cognitive reach. ${ }^{10}$ Therefore, the problem of universals is related to the three remaining "strata": linguistic symbols, objective meanings, and phenomenal realities.

Bocheński assumes that a linguistic symbol can be considered as general if and only if (at least) two symbols of the same shape (as the given symbol) are predicated of two different objects.

This idea can be expressed more precisely as follows: for any $x$ and $y: x$ is a general symbol of $y$ if and only if there is at least one $z, t, u w$, such that:

(a) $z$ and $t$ are $y$-a symbols;

(b) $x, z, t$ are equiform;

(c) $z$ is predictated of $u$ and $t$ is predicated of $w$;

(d) $u$ is different from $w$.

This can be written formally as follows:

(1) $\forall x, y\{O g(x, y) \equiv \exists z, t, u, w[z S y \wedge t S y \wedge z R x \wedge t R x \wedge z O u \wedge t O w \wedge t \neq u]\} .^{11}$

In that case, according to Bocheński, two questions arises:

(a) are the general symbols components of any effective language ${ }^{12}$;

(b) what kind of general symbols have to be components of an effective language.

The first of these questions has an easy solution: in any effective language there are some general symbols; for instance without general symbols no classification would be possible. The second issue is much more complex, but also more important for the problems in question here: any opportunity to get rid of the general symbols (and hence, also, their meanings and denotations) from specific languages would be tantamount to "cancelling" the problem for those languages.

According to Bocheński, this issue can be reformulated in the following question:

(b') 'does any effective language have to have a primitive syntactic category of general terms'?

\footnotetext{
${ }^{10}$ It can be added that transcendent beings remain beyond the perspective of ontological individualism.

11 Interpretation of symbols: ' $O g$ ' - '...is a general symbol', ' $S$ ' - '...is a symbol...', ' $R$ ' - '...is isomorphic with...', ' $O$ ' - '...is predicated of...'.

12 An effective language is the one in which it is possible to formulate science, including mathematics.
} 
In resolving this issue Bocheński focuses on one selected effective language, namely, Russell's and Whitehead's Principiorum language. It includes the following syntactic categories in it:

(a) individual variables: ' $x$ ', ' $y$ '...;

(b) one-place functors for names: ' $\varphi$ ', ' $\psi$ '...;

(c) existential quantifier: ' $\exists$ ';

(d) sentence variables: ' $p$ ', ' $q$ ';

(e) two-place functors for sentences: 'l'.

The problem of universals, according to Bocheński, arises with respect to symbols of group (a), (c), (d), and (e). ${ }^{13}$ Therefore, it arises only in relation to the symbols of functors with nominal arguments (' $\varphi$ ', ' $\psi$ '...).

In the " $\lambda \varepsilon \kappa \tau \alpha$ " "stratum" the following further questions appear:

(a) are there any meanings at all?

(b) are there any general meanings?

Because the word 'meaning' is itself ambiguous its meaning has first to be determined. Bocheński proposes to divide meanings into:

( $\alpha$ ) syntactic meanings (the meanings of terms comes down to a set of linguistic rules applicable to these terms);

( $\beta$ ) semantic meanings (syntactic rules do not exhaust meanings of terms; these meanings are also determined by suitable interpretations of the given language).

Semantic meanings come in two varieties:

(i) operational semantic meanings ${ }^{14}$;

(ii) eidetic meanings. ${ }^{15}$

Bocheński's approach with regard to the issue (a) can be expressed in the form of the following statements:

(2) Some symbols have only syntactic meanings, and thus also:

(3) Some symbols do not have semantic meaning;

(4) Each symbol with semantic meaning has also operational semantic meaning;

(5) Some symbols have eidetic meaning;

(6) Some symbols do not have eidetic meaning.

\footnotetext{
13 Individual variables represent names of individual objects, the quantifier symbol is only used to determine the existence of something without informing about its nature (in turn, general quantifier can be eliminated by the existential quantifier and negation which, subsequently, is defined by the functor 'l'), symbols of sentence variables can be replaced by functors from the (b) group with individual names as their functors. Symbol 'l' causes some interpretational difficulties not connected with the foregoing matter.

14 It can be assumed that a given expression has an operational semantic meaning if and only if the sentence with the relevant expression as a component has its method of verification (the meaning of $p=$ the method of verification of $p$ ).

15 The eidetic meaning of an expression would be "what is understood by a symbol" and thanks to which this expression, apart from the method of verification, possesses a semantic correlate. Compare (Bocheński 1993a, 87-88).
} 
To those who deny the existence of eidetic meanings, claiming that machines, on the basis of stimuli replacing symbols, can behave just like people, Bocheński says that "this has never been proved that it is possible in any case" (Bocheński 1993a, $88)$.

In addition Bocheński claims, that:

(7) "a direct overview of what takes place in us when we understand a symbol leads us to adopt eidetic meanings";

(8) "there is no a pragmatic test for the opposite claim formulated by the [...] opponents";

(9) "the entire theory of verifiability is so hopelessly murky that we can not see any reason that would lead us to accept something as poetic and romantic" (Bocheński 1993a, 88-89).

Now Bocheński transforms the (b) issue into the question:

(b') are there are any eidetic meanings?,

which further divides into specific problems:

(b'1) which symbols of language must be considered as having eidetic meaning;

(b'2) on the assumption that there is a non-empty class of such eidetically meaningful symbols, should it be assumed that the elements of this class are unambiguous symbols, i.e. do two equiform symbols have to have the same meaning?

Bocheński answers these two questions positively. First, it is not possible to eliminate even one-place functors for names. For the metalinguistic rules the following circumstance arises: metalinguistic sentences objectively refer to certain bodies, namely to inscriptions; expressions of the type 'shape of the letter T' must have semantic meaning, because otherwise we could not adjudicate "which pile of dried ink is the letter $t$ " (Bocheński 1993a, 90).

Second, the hypothesis about the ambiguity of equiform symbols is refuted by the following arguments:

- assuming the ambiguity of symbols it would be difficult to explain the fact of communication;

- the hypothesis about the ambiguity of symbols must itself be formulated in unambiguous language, otherwise it would be inexplicable (would be babble).

However, with regard to the "stratum" of phenomenal realities, Bocheński makes the following claims:

(10) "Some of our classifications of specific objects within scientific languages are not completely arbitrary."

(11) "Whenever classification is not completely arbitrary, something in the classifiable objects justifies the classification."

(12) "There are objects which are linked together in such a manner that this relation justifies our classification.” (Bocheński 1993a, 92-94). 
Bocheński justifies claim (10) by the following simple thought experiment. Let us assume that we are dealing with three arbitrarily specified objects: $x, y$ and $z$, and with three classes selected just as arbitrarily: $\varphi, \psi$ and $\chi$. Let us further assume that in the considered domain the following statements are true:

(i) $\exists x(\sim \varphi x \wedge \psi x \wedge \chi x)$;

(ii) $\exists y(\varphi y \wedge \sim \psi y \wedge \chi y)$;

(iii) $\exists z(\varphi z \wedge \psi z \wedge \sim \chi z)$.

Our classification will be as follows:

- $\varphi=\{y, z\}$

- $\psi=\{x, z\}$

- $\chi=\{x, y\}$

- $\sim \varphi=\{x\}$;

- $\sim \psi=\{y\}$;

- $\sim \chi=\{z\}$.

It is easy to see that the assumed objects, classes, and statements are completely arbitrarily. However, the classification itself, based on the assumed statements, is no longer arbitrary: "if we classify objects in terms of $\chi$, it is not arbitrary that we lay $z$ aside," it is something "which does not depend on our will" (Bocheński 1993a, 92-93). Justification of claim (11) consists in Bocheński's rejection in this regard of epistemological idealism and Platonism. Because claim (12) follows from claim (11), it should be considered as well-grounded. And claim (12) says that there is a relation which justifies our classifications. The problem of universals for the real world ipso facto comes down to the question, what this relation is. Two competing theories - the so-called similarity theory and the identity theory-answer this question.

According to the similarity theory, a relation that holds between the classified objects depends on their similarity (of course, it is a reflexive and symmetrical relation). At the same time this theory denies that there is allegedly any total or even partial identity between classified objects. Whereas the identity theory says that the relation that binds classified items is the identity of "aspects" of these items (in other words: the identity of some of their properties), where this relation holds between these "aspects", not between the classified objects.

An important difference between these theories, according to Bocheński, is that the identity theory makes ontological assumptions that the similarity theory does not. This is because within the identity theory the existence of properties is assumed, whereas in the similarity theory there is no such assumption. Indeed, some similarity theories simply reject the existence of properties. ${ }^{16}$

A clear example of the similarity theory-according to Bocheński-is Leśniewski's ontology. In that theory, the world is presented as not stratified, deprived of properties, consisting only of individuals. For this theory, there is a suitable criterion for formulation, namely Quine's criterion: "to be is to be the value of a variable"

\footnotetext{
${ }^{16}$ Hereby Bocheński takes Leśniewski's ontology as an example. For a reconciliation of the identity theory with nominalism in connection with Leśniewski's ontology see (Sinisi 1962).
} 
(Bocheński 1993a, 96). According to Bocheński, Goodman and Quine interpret functors not as variables but as "schematic letters" or "imitation letters," indicating thereby that they do not have correlates in the phenomenal world (Goodman and Quine 1947). Bocheński claims that Goodman-Quine's approach must be rejected for two reasons. First, it is rejected on intuitive grounds; the world must be stratified: when we find ' $\varphi a$ ' to be true, there must be in the world something which corresponds both to ' $a$ ' and to ' $\varphi$ '. Second, as indicated above, each component of an effective language can be effectively reduced by analysis to one of the five syntactic categories of Principia: ' $x$ ', ' $y$ '...; ' $\varphi$ ', ' $\psi$ '...; ' $\exists$ '; ' $p$ ', ' $q$ '; 'l'. In turn, individual names "can be replaced by descriptions, then the descriptions are replaced, contextually by formulas containing only variables, functors, quantifiers, and a vertical bar (Sheffer's stroke)" (Bocheński 1993a, 97). Ultimately, all that can be said about the world can be said with the use of functors; we do not need individual names, they only play the role of variables as "empty places" (they have a purely operational meaning).

In this case, since individual variables function only as "empty places" and-on the basis of Quine's criterion-nothing in the world corresponds to functors, it would be consistently acknowledged that none of our assertions about the world really assert anything. Bocheński rejects this conception, because it leads to extreme scepticism. At the same time, Quine's criterion must be rejected too: if the world is stratified and is composed of at least two types of entities of different ontological status, the expression 'to exist' in relation to these two types has to have different meanings. Quine's criterion, which can be used for individuals, is not applicable to the "stratum" of properties; "because existence, in the case of property, is not the value of variable, but is the determination of value for a variable" (Bocheński 1993a, 98). Bocheński writes: "So to say that there exists something that is denoted by $\varphi$, is equivalent to saying ' $\exists x \varphi x$ ', not to ' $\exists \varphi \varphi x$ '. The latter formula is deceptive, because it seems to assign the same mode of existence to a property that is assigned to value $x$. When we ' $\exists \varphi \varphi x$ ', a property is brought to an object" (Bocheński 1993a, 98).

Generally, Bocheński rejected the similarity theory for the following two reasons. The first is the circumstance that "any clear statement about classified objects becomes unmanageable and complex" (Bocheński 1993a, 99) ${ }^{17}$ For example, in so far as an identity theorist would be willing to accept the sentence:

$$
\exists x, y[\varphi x \wedge \varphi y \wedge x \neq y],
$$

a similarity theorist would have to treat the sentence (13) as the abbreviation of the following sentence:

$$
\exists f, g, x, y[f H g \wedge f P x \wedge g P y \wedge x \neq y] .
$$

In the case of classification of three objects, a supporter of the similarity theory would have to accept a very complex sentence:

\footnotetext{
17 According to Bocheński, the meaning of predicate symbols used in further statements is the same as the meaning of relevant symbols used in statement (1).
} 
$\exists f, g, h, x, y, z[f H g \wedge g H h \wedge h H x \wedge f P x \wedge g P y \wedge h P z \wedge x \neq y \wedge y \neq z \wedge$ $z \neq x]$,

while the following thesis would suffice for the identity theorist:

$$
\exists x, y, z[\varphi x \wedge \varphi y \wedge \varphi z \wedge x \neq y \wedge y \neq z \wedge z \neq x] .
$$

Another reason to reject the similarity theory is that "the similarity theory cannot be formulated in an other way than in terms of the identity theory" (Bocheński 1993a, 100), which is self-evident as soon as one investigates the construction of formulas (14) and (15) above (de facto the similarity theory assumes the identity theory).

However, the identity theory faces the following theoretical difficulty. Suppose that the following statement is true:

$$
\exists x, y[\varphi x \wedge \varphi y \wedge x \neq y] \text {. }
$$

Therefore, there are two non-identical individuals $(x, y)$ which have an identical property $(\varphi)$. Since the individuals $(x, y)$ are not identical, there is at least one such property $(e . g . \psi)$ which is had by one individual and not by the second one. Then suppose that in addition to the statement (13), the following sentences are true:

(17) $\exists x[\varphi x \wedge \psi x]$;

(18) $\exists y[\varphi y \wedge \sim \psi y]$.

Now let us call the ' $\theta$ ' property the property of 'existing in $x$ together with $\psi$ '. This property (of the second level) will be had by $\varphi$ in $x$, but not had by $\varphi$ in $y$. Therefore, there is at least one such property $\theta$ that $\theta$ is had by $\varphi$ in $x$, but not had by $\varphi$ in $y$. It follows from this further that $\varphi$ possessed by $x$ is not identical with $\varphi$ possessed by $y$. This is contrary to the initial findings. This example suggests that identity with regard to individuals is not the same as identity with respect to properties. The second identity $(\underset{S}{\bar{S}})$ cannot—as displayed above-be defined as follows:

$$
\begin{aligned}
& \varphi \underset{\bar{S}}{\psi} \equiv \forall \theta[\theta(\varphi) \equiv \theta(\psi)] \\
& \varphi \underset{\bar{S}}{\overline{\bar{S}}} \psi \equiv \forall \theta\{\theta \in \kappa \rightarrow[\theta(\varphi) \equiv \theta(\psi)]\} .{ }^{18}
\end{aligned}
$$

It seems that the required definition should be formulated as follows:

$$
\varphi \underset{\bar{S}}{=} \equiv \forall x[\varphi x \equiv \psi x] .
$$

According to Bocheński, if statement (21), within the framework of "applied" logic entailed statement (13), the inconsistency indicated above would still remain.

The result of these considerations-according to Bocheński-is the thesis about existence of two kinds of identity: $N$-identity characteristic of individuals (defined in

\footnotetext{
${ }^{18}$ Bocheński writes: "If objects are, let's say, scarlet, and thereby, scarletness is common to them, this does not imply at all that each shade of scarlet in one case will be also the shade of scarlet in the second case." See (Bocheński 1993a, 103). Definability of ' $k$ ' in formula (20) is problematic; this symbol cannot be defined extensionally without referring to formulas of the ' $\varphi x \wedge \varphi y$ ' type.
} 
(19)) and S-identity characteristic of properties (defined in (20) and (21)). The result is also a fundamental distinction between two ontological "strata": the "stratum" of objects and that of properties. Yet a further result is the thesis that extreme realism and nominalism fail to formulate the problem of universals at all, whereas for an ontological individualist this issue is first of all the matter of explaining the nature of identity.

Bocheński's analysis of the problem of raises a few doubts. First, in my opinion, Bocheński goes too far when he links Leśniewski's ontology with the formal features of Principia and with Quine's ontological criterion as well as with Quine and Goodman's "Steps toward a constructive nominalism." Quine's criterion concerns first-level theory, whilst in Leśniewski's language it is easy to quantify over variables of any type and in this connection the criterion in question should be treated with reservation within ontology. Additionally, it is not prejudged whether within ontology the range of quantification covers only the domain of individuals. In ontology, as far as I know, a reduction of individual names to relevant variables and functors, as proposed by Bocheński, cannot be carried out by means of descriptions: this is due to differences in the syntactic construction of ontology and the Principia. Furthermore Leśniewski-unlike Quine and Goodman-constructed systems of universal importance, whereas Quine and Goodman attempted merely to provide nominalist definitions of a few terms of predicate logic.

As far as the identity theory is concerned, in ontology, compared with the predicate calculus, there are at least three kinds of identity. We can speak of singular (ordinary) identity, "strong" (extensional) identity and "weak" identity. ${ }^{19}$ Perhaps the different kinds of identity defined in Leśniewski's ontology would allow for a more accurate analysis of the problems associated with the identity and similarity theories. Unfortunately, Bocheński omitted this possibility in his text. As for quantification over properties, it can be argued - contrary to Bocheński-that such a procedure does not have to mean reification of properties. This would be the case were we to transform Quine's criterion into a criterion claiming that to be a thing means the same as to be the value of a quantified variable. Quine's ontological criterion is applicable only to existence, not to the nature of existing objects, recognized as values of quantified variables.

\section{Comparison of the presented approaches}

The analyses presented above differ significantly, but they also have some points of convergence that can easily escape attention when they are examined superficially. But first let us look at some rather obvious differences.

Firstly, these reconstructions differ as to the purpose for which they were intended. In regard to PTC, Bocheński's clearly stated objective was to report and interpret "St. Thomas Aquinas' ontological theory of universals." He considers it

\footnotetext{
19 The definition of singular identity: $\forall a, b\{a=b \equiv[(a \varepsilon b) \wedge(b \varepsilon a)]\}-a$ is the same object as $b$; the definition of strong identity: $\forall a, b\langle a \bullet b \equiv \Sigma c\{(c \varepsilon a) \wedge \forall c[(c \varepsilon a) \equiv(c \varepsilon b)]\}$-only each $a$ is $b$; the definition of weak identity: $\forall a, b\{a \bigcirc b \equiv \forall c[(c \varepsilon a) \equiv(c \varepsilon b)]\}$-only any $a$ is $b$.
} 
approvingly, explicite confessing that he recognizes Aquinas' approach to be the "solely accurate" one. The task of $\mathrm{ZP}$ - at least overtly-was not so much to resolve the issue, but rather to formulate it clearly and unambiguously. Although the results, which Bocheński obtained in $\mathrm{ZP}$, suggest a realist solution, the analysis itself can be can be regarded, to some extent, as ontologically neutral.

Secondly, both texts differ significantly in respect to the adopted method of inquiry. In PTC this method is largely a historical analysis, supported with ontological interpretations and reconstructions within first-level predicate calculus 1 with identity. However, in ZP, the analysis is carried out only by logical analysis supported with the formalism of Principia, but-and this is noteworthy-the analysis goes well beyond the the first level language.

Thirdly, these papers vary in scope and granularity of the issues discussed. PTC directly provides analyses and ontological conclusions, while ZP puts such solutions-considered as possible-in the background, taking as its salient subject matter the five aforementioned "strata": language symbols, subjective mental entities, objective meanings, phenomenal realities and transcendent entities. Therefore, in $\mathrm{ZP}$, the subject matter is extended to a broad spectrum of semantic issues.

Fourthly, both papers differ significantly in regard to the philosophical contexts in which they were set. Regarding PTC, the immediate context of Bocheński's analysis are the philosophical discussions held within the Lvov-Warsaw School, in particular, disputes concerning universals, involving Ajdukiewicz, Kotarbinski, Leśniewski, Łukasiewicz, and Ingarden. By contrast, the analyses included in ZP have a much wider context: they include not only the legacy of Lvov-Warsaw School, marked by the references to Leśniewski's approaches, but also refer to discussions that took place in the first half of the twentieth century within mainstream analytic philosophy.

Despite these differences, both papers have several features in common. First, their tenor-explicitly in PTC, implicitly in ZP-is realist. In both texts Bocheński represented himself as a moderate realist. Second, both papers reduce the problem of universals to an adequate ontological interpretation of properties. Only the manner of the reduction differs: in PTC it consists in extracting the notion of content of a property from the notion of a property, while in $\mathrm{ZP}$ the method is to consider identity for individuals and properties (vide: involvement of the term of S-identity). Third, both papers are characterized by a fairly clear negative evaluation of nominalists' reconstructive efforts: in the case of PTC the reference is to Kotarbiński's analysis, while in ZP it is directed against the reconstructions by Quine, Goodman, and Leśniewski.

\section{Conclusion: the lesson from Bocheński}

The question naturally arises whether Bocheński's analysis presents, from the point of view of a contemporary philosopher, any particular intellectual value. I daresay it does. Here are some reasons why I think so. Firstly, the distinction, in accordance with Aquinas, between particular properties and the contents of these properties 
anticipates, in my opinion, the doctrine which admits properties as tropes and properties as universals as fundamental ontological categories. ${ }^{20}$ Incidentally, I might add here that I support this view. There remains, of course, the question of the coherent development of an approach of this kind, but Bocheński provided the general outline.

Secondly, it is worth bearing in mind, even from a contemporary point of view, that according to St Thomas whenever we attribute something to something we attribute to it abstract properties (i.e. contents). Language is not and cannot be an exact copy (model) of reality. Perhaps this fact is partly responsible for the ongoing philosophical disputes within which the said complication is ignored. Although Bocheński offers no recipes, he does provide a valuable diagnosis.

Thirdly, Bocheński rightly realises - while considering nominalist argumentsthat delivering appropriate paraphrases or accepting this or that formal reconstruction of everyday speach is not and cannot be in itself a solution to ontological problems. An adequate paraphrase is always a symmetrical relation, and the possible reconstruction of natural language based on the theory of syntactic categories, which almost automatically allows for nominalistic reasoning, bears the marks of the petitionis principii fallacy (Bocheński 1949, 278). Moreover, similar reservations can be formulated not only with regard to nominalist attempts.

I would like to end my reconstructions of Bocheński's analysis with two additional comments. ${ }^{21}$ The first concerns the conception which maintains that there is a difference between particular properties and contents of properties. Now one can accept all of Bocheński's findings in this matter but continue beyond the point where he stopped. Because, contrary to Bocheński, we can, on the one hand, readily accept the idea of language as an inaccurate copy of reality, but, on the other hand, we need not refrain form exploring ontologically the difference in question. ${ }^{22}$ Bocheński did not do so.

The second critical comment concerns the concept of S-identity. I think that Bocheński rightly sees properties as the core of the problem of universals when he distinguishes the specific notion of identity for properties. However, I do not think the very concept of $S$-identity is the key to solve the relevant problem. I suppose that Bocheński's recourse to this concept is the effect of having abandoned ${ }^{23}$-at least implicitly - the distinction between properties as tropes and properties as contents. In my opinion, the basis for further analysis of the problem of universals should be sought precisely in this difference, not in S-identity.

\footnotetext{
${ }^{20}$ For an approach of this type see e.g. (Lowe 2006).

21 In my opinion, the problem whether the thesis of ontological individualism does not conflict with an immanent realism approach, and whether using some types of functors in a given language entails any ontological commitments, requires a separate consideration. This last point is of particular importance in light of the possibility, indicated by Bocheński, to paraphrase statements with general names into statements without them.

22 An attempt of analyses of this kind can be found in (Lowe 2009, ch. 11 and 12).

23 Interestingly, there appears a distinction in ZP, footnote 5, between two concepts of property: property as proprium and property as nota.
} 
Open Access This article is distributed under the terms of the Creative Commons Attribution License which permits any use, distribution, and reproduction in any medium, provided the original author(s) and the source are credited.

\section{References}

Ajdukiewicz, K. (1930). Reizm. Studium krytyczne: Elementy teorii poznania, logiki formalnej i metodologii nauk (Reism. A critical study: The Elements of the theory of knowledge, formal logie and the methodology of science) by Tadeusz Kotarbinski Przeglad Filozoficzny, 33, 140-160.

Ajdukiewicz, K. (1932). W obronie uniwersaliów (In defense of universals). Ruch Filozoficzny, 13, 40b41b.

Ajdukiewicz, K. (1934). W sprawie uniwersaliów (The matter of universals). Przeglad Filozoficzny, 37, 219-234.

Armstrong, D. M. (2001). Universals as Attributes. In M. J. Loux (Ed.), Metaphysics. Contemporary Readings (pp. 65-69). London, New York: Routledge.

Bocheński, J. M. (1935). Zagadnienie przyczynowości u neoscholastyków (Neo-scholastics on the question of causality). Przeglad Filozoficzny, 38, 125-134.

Bocheński, J. M. (1938). Powszechniki jako treści cech w filozofii św. Tomasza z Akwinu (Universals as the contents of properties in the philosophy of St. Thomas Acquinas). Przeglad filozoficzny, 41, $136-149$.

Bocheński, J. M. (1949). On the syntactical categories. The New Scholasticism, 23, 257-280.

Bocheński, J. M. (1956). The problem of universals. In J. M. Bocheński, A. Church, \& N. Goodman (Eds.), The problem of universals (pp. 33-54). Notre Dame: Notre Dame Press.

Bocheński, J. M. (1993a). Zagadnienie powszechników [trans. T. Baszniak of Bocheński, J. M. (1956)]. In J. M. Bocheński (Ed.), Logika i filozofia. Wybór pism (Logic and philosophy. Selected papers; elaborated by. J. Parys) (pp. 79-105). Warszawa: PWN.

Bocheński, J. M. (1993b). O filozofii analitycznej (On analytical philosophy) [trans. D. Gabler]. In J. M. Bocheński (Ed.), Logika i filozofia. Wybór pism (elaborated by. J. Parys) (pp. 35-49). Warszawa: PWN.

Borowski, M. (1921). O przedmiotach fizycznych, psychicznych, idealnych i fikcyjnych (On physical, psychic, and fictional objects). Przeglad Filozoficzny, 24, 139-163.

Goodman, N., \& Quine, W. V. O. (1947). Steps toward a constructive nominalism. Journal of Symbolic Logic, 12, 105-122.

Grygianiec, M. (2001). Kotarbiński przeciw uniwersaliom (Kotarbiński as an opponent of universals). Przeglad Filozoficzny: Nowa Seria, 3, 95-114.

Jadacki, J. J. (1998). Orientacje $i$ doktryny filozoficzne. Z dziejów myśli polskiej (Philosophical orientations and doctrines. From the history of Polish philosophy). Warszawa: WFiS UW.

Kotarbiński, T. (1921). Sprawa istnienia przedmiotów idealnych (On the existence of ideal objects). In Księga pamiątkowa ku uczczeniu 25-letniej działalności nauczycielskiej na katedrze filozofii $w$ Uniwersytecie Lwowskim Kazimierza Twardowskiego, Lwów, 149-170.

Lejewski, Cz. (1990). On the Dramatic Stage in the Development of Kotarbiński's Pansomatism. In J. Woleński (Ed.), Kotarbiński: Logic, Semantics and Ontology (pp. 69-83). Nijhoff International Philosophy Series. Vol. 40. Dordrecht: Kluwer.

Leśniewski, St. (1913). Krytyka logicznej zasady wyłączonego środka (A critique of the logical principle of the excluded middle). Przeglad Filozoficzny, 16, 315-352.

Lowe, E. J. (2006). Four-category ontology. A metaphysical foundation for natural science. Oxford: Oxford University Press.

Lowe, E. J. (2009). More kinds of being: A further study of individuation, identity, and the logic of sortal terms. Oxford: Wiley-Blackwell.

Łukasiewicz, J. (1910). O zasadzie wyłączonego środka (On the principle of the excluded middle). Przeglad Filozoficzny, 13, 372-373.

Sinisi, V. F. (1962). Nominalism and common names. Philosophical Review, 71, 230-235.

Twardowski, K. (1894). Zur Lehre vom Inhalt und Gegenstand der Vorstellungen. Eine psychologische Untersuchung. Wien: Alfred Hölder (reprint: (1982) München-Wien: Philosophia Verlag).

Wolak, Z. (1993). Neotomizm a Szkoła Lwowsko-Warszawska (Neo-Thomism and the Lvov-Warsaw School). Kraków: OBI, PAT. 